\title{
Analisis Dramatistic Pentad Unsur Konsumerisme Dalam Film They Live 1988
}

\author{
Alan Satjakoesoemah ${ }^{1}$, Sarah Vania Rizky ${ }^{2,}$ Elviera Joelanda Sharinta ${ }^{3}$ \\ ${ }^{1}$ LSPR Business and Communication Institute, e-mail: rdalansaputra@gmail.com \\ ${ }^{2}$ LSPR Business and Communication Institute, e-mail: sarahvania226@gmail.com \\ ${ }^{3}$ LSPR Business and Communication Institute, e-mail: elvierajoesha@gmail.com
}

\begin{abstract}
Konsumerisme adalah suatu pemahaman yang dimana individu atau kelompok secara sadar melakukan kegiatan konsumsi barang-barang hasil produksi yang berlebihan, kemudian menumbuhkan efek candu pada manusia terhadap suatu produk yang berakibat pada sulitnya menghilangkan sifat ketergantungan dan candu pada produk itu. Hal tersebut sama seperti yang dikemukakan oleh Jean Baudrillard sebagai kritik terhadap konsumerisme bahwa terdapat realita semu pada masyarakat posmodern. Namun tanpa disadari, nilai-nilai tersebut sudah menyebar luas dalam berbagai media massa, salah satunya film. Berdasarkan latar belakang tersebut penulis melakukan kajian terhadap film They Live guna melihat bagaimana film tersebut menggambarkan unsur konsumerisme. Penelitian ini menggunakan metode kualitatif dengan teknik analisa pentad dramatisme Kenneth Burke. Di akhir penelitian ini, dapat disimpulkan bahwa film They Live mengandung adegan-adegan yang menggambarkan bagaimana konsumerisme mempengaruhi kehidupan masyarakat dan terdapat relevansi tentang apa yang digambarkan di dalam film They Live pada tahun 1988 tersebut dengan realita era masa kini.
\end{abstract}

Keywords: They Live, konsumerisme, kritik konsumerisme, jean baudrillard, analisis dramatistic pentad

\begin{abstract}
Consumerism is an understanding whereby individuals or groups consciously engage in excessive consumption of goods, and then develop an opium effect on humans against a product which results in the difficulty of eliminating the nature of addiction in the product. It is a disease psyches that unknowingly infect humans in their daily lives. This is the same as that of Jean Baudrillard as a criticism of consumerism that there is a false reality in posmodern society. However unknowingly, these values have already widespread in various mass media, one of them is in a movie. Based on this background, the author conducted a review of the movie They Live to see how the movie depicts the element of consumerism. This study uses qualitative methods with Kenneth Burke's dramatistic pentad analysis technique. At the end of this study, it can be concluded that They Live movie contains scenes that illustrate how consumerism affects people's lives and there is relevance about what is depicted in the 1988 They Live movie with the realities of the present era
\end{abstract}

Keywords: They Live, consumerism, critics on consumerism, jean baudrillard, dramatistic pentad analysis, kenneth burke 


\section{PENDAHULUAN}

Pada tahun 1988 terdapat sebuah film fiksi ilmiah They Live (1988) yang kemudian menjadi sebuah film cult classic, arahan sutradara sekaligus penulis skenario John Carpenter asal Amerika Serikat yang menarik banyak perhatian serta menjadi inspirasi bagi banyak sutradara muda. Film ini menceritakan tentang sekelompok ras makhluk luar angkasa yang menyamar menjadi manusia dan menciptakan budaya konsumerisme sebagai alat untuk menaklukan dan mengeksploitasi manusia untuk meraup sumber daya alam bumi. Makhluk luar angkasa tersebut menggunakan suatu sinyal frekuensi misterius yang berfungsi sebagai semacam alat kontrol pikiran, membuat manusia tidak dapat melihat wujud asli mereka dan membuat manusia tunduk pada pesan-pesan subliminal yang disebarkan oleh makhluk luar angkasa tersebut melalui perantara media.

Cerita ini berpusat pada seorang tunawisma nomaden bernama John Nada, yang pergi ke kota Los Angeles untuk mencari pekerjaan namun setelah melalui hari-harinya di Los Angeles ia menemukan sebuah kacamata yang dapat melihat realita dunia sebagaimana aslinya, yang ternyata melalui kacamata tersebut, dunia dipenuhi oleh banyak pesan-pesan yang mengandung unsur konsumerisme, pesan-pesan subliminal tersebut terdapat di majalah, produk makanan, papan iklan, poster dan lain sebagainya. Situasi dan kondisi masyarakat yang digambarkan di dalam film They Live terlihat memperihatinkan, kemiskinan dan kriminalitas merajalela namun golongan masyarakat kaya semakin kaya, tidak nampak golongan masyarakat kelas tengah, hanya ada kelas atas dan bawah, kaya dan miskin. Fenomena yang digambarkan di dalam film tersebut dipengaruhi oleh masyarakat konsumeris.

Film 'They Live' memiliki banyak unsur social politik dan salah satunya adalah konsumerisme dilihat dari pesan-pesan subliminal yang ada di dalam synopsis dan film tersebut, seperti "OBEY", "CONFORM", "MARRY AND REPRODUCE", yang mengandung unsur konsumerisme.

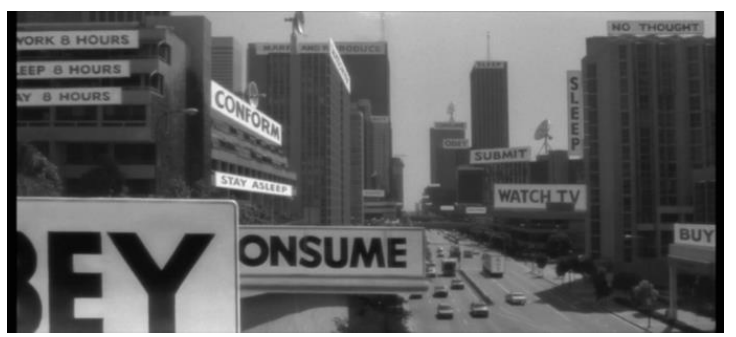

Gambar 1. "Sunglasses Scene" 33:04, dari film 'They Live'

Media berperan penting dalam mengkonstruksi paradigma orang-orang dengan mengkonversi halhal tersier menjadi primer, juga telah menjadi salah satu alasan kenapa penulis mengambil unsur konsumerisme sebagai pokok bahasan skripsi adalah karena fenomena konsumerisme yang ada dalam film tersebut unik, mengapa? Karena fenomena konsumerisme ternyata sudah di antisipasi dari era 80-an dan terus terjadi seiring dengan berjalannya waktu dan perkembangan teknologi media dan informasi hingga era masa kini. Konsumerisme yang di presentasikan dalam film buatan tahun 1988 'They Live' tersebut relevan dengan era masa kini yang dimana teknologi informasi tersebar luas di belahan dunia manapun, bahwa konsumerisme sebagai hasil dari kapitalisme dan didukung oleh media terjadi di berbagai tempat, bukan hanya di Amerika Serikat saja.

Peneliti mengambil demikian dari sudut pandang bahwa konsumerisme itu tidak lain hanyalah realita semu yang di buat-buat yang dibantu oleh media dan terus berjalan hingga saat ini.Sebelumnya penelitian mengenai topik konsumerisme dan film yang menggunakan teori dramatisme pentad sudah ada dan banyak, seperti contohnya adalah penelitian Pawanti (2013) mengenai bagaimana pemaparan pemikiran Jean Baudrillard mengenai konsumerisme dan juga dari penelitian dramatisme pentad ada juga dari hasil penelitian Jonathan Ritchie (2015) yang meneliti propaganda Amerika Serikat dalam film Saving Private Ryan yang menggunakan teori dramatisme pentad. Peneliti menggunakan dua teori dalam penelitian ini yaitu teori masyarakat konsumsen dari Jean Baudrillard dan teori dramatisme pentad dari Burke. Ketika peneliti melihat film 'They Live' memiliki unsur konsumerisme, peneliti menganalisisnya menggunakan teori dramatisme pentad untuk menguraikan dan menjelaskan konsumerisme yang terdapat dalam beberapa adegan film 'They Live, dan teori masyarakat konsumsi Jean Baudrillard untuk menjelaskan fenomena konsumerisme itu sendiri.

Fenomena konsumerisme dalam film tersebut dapat dijelaskan dengan teori-teori seorang filsuf asal Prancis, Jean Baudrillard (1998), dalam bukunya The Consumer Society: Myths and Structures, masyarakat era modern membeli barang dan jasa tidak semata untuk kebutuhan atau membeli karena barang dan jasa tersebut terdapat nilai gunanya, melainkan untuk gaya hidup, trend, prestise dan gengsi semata, dan dari hal-hal tersebut terbentuklah gaya hidup yang disebut dengan konsumerisme yang dipicu oleh adanya mediamedia yang mempengaruhi paradigma dan sikap masyarakat dalam membeli barang dan jasa dan media tersebut adalah media elektronik maupun media informasi. Namun, media selain memicu masyarakat untuk menjadi konsumtif, media yang seperti itu juga berangkat dari sifat egois masyarakat sendiri, jadi media menurut Baudrillard (1998) adalah sebuah cermin bagi masyarakat sekaligus sebagai alat (yang dihasilkan dari sifat masyarakat tersebut) untuk mempengaruhi masyarakat dalam kehidupan konsumer. Kemudian, 
dalam The System of Objects, Baudrillard (1996) menguraikan bagaimana konsumen membeli ke dalam "kode" tanda atau simbol daripada makna dan nilai guna dari objek itu sendiri. Analisisnya tentang proses adalah simbol berhenti mengarah ke objek atau simbol yang ada di belakangnya, melainkan pada tanda-tanda lain yang bersamasama membentuk sebuah "kode" yang kohesif namun kacau, yang berpuncak pada "pembunuhan realitas" (Baudrillard, 1996).

Kenneth Burke (1969) mengidentifikasi teorinya yaitu Dramatisme sebagai alat untuk mengetahui apa dan mengapa orang-orang melakukan sesuatu dilihat dari motif mereka. Hal yang diidentifikasi salah satunya adalah bahasa. Seperti yang dijelaskan oleh Em Griffin (2012), bahwa Burke meyakini bahasa sebagai respon strategis atau penting di suatu situasi yang spesifik. Konsep utama Burke dalam dramatism tertuju pada adanya simbol, bahasa, dan komunikasi. Dimulai dari adanya pengenalan kata yaitu tindakan (action) dan gerakan (motion). Dramatisme membantu peneliti untuk mengamati suatu kejadian dengan lebih cermat dan terperinci.

Berdasarkan latar belakang dan teori yang telah penulis uraikan di atas maka penulis merumuskan masalah sebagai "Bagaimana konsumerisme yang terdapat di dalam film They Live (1988) dan apa relevansinya dengan era masa kini?". Dalam menjalankan penelitian ini, penulis memiliki tujuan-tujuan, yaitu untuk menganalisa dan mengetahui pesan-pesan konsumerisme apa saja yang terdapat di dalam film karya John Carpenter, They Live tahun 1988 dan untuk mengetahui relevansi konsumerisme yang digambarkan di dalam film They Live (1988) dengan realita masa kini.

\section{METODOLOGI PENELITIAN}

Dalam penelitian ini penulis akan melihat bagaimana data-data di gunakan dan di analisa dalam penelitian ini. Pada penelitian yang berjudul Analisis Dramatistic Pentad Unsur Konsumerisme dalam Film They Live (1988) penulis menggunakan metode kualitatif. Daymon dan Holloway (2011) dalam bukunya yang berjudul Qualitative Research Methods in Public Relations and Marketing Communications menjelaskan mengenai metode penelitian kualitatif yaitu, penelitian kualitatif berkatian dengan pandangan interpretative tentang dunia dan sekitarnya. Kualitatif tertarik dalam mengeksplorasi hubungan makda dan komunikasi, dan bagaimana realitas social dibangun dari sudut pandang orang-orang yang sedang dipelajari. Selain itu penelitian kualitatif dapat digunakan dalam sebuah proyek penelitian atau kombinasi dengan penelitian kuantitatif (Daymon \& Holloway, 2011).

Dalam penelitian ini, penulis menggunakan teknik pengumpulan data melalui metode pengumpulan data primer dan pengumpulan data sekunder dan data sekunder untuk mendukung hasil yang diperoleh yaitu melalui buku, situs internet dan artikel jurnal.

Dalam teknik analisis data penulis menggunakan teknik analisis dramatistik pentad untuk menganalisa film They Live (1988). Dramatistik mempunyai sudut pandang atau pemikiran bahwa kehidupan kita adalah drama, dengan memberi kritik terhada setiap spesifikasi pola dan tingkah laku yang di demonstrasikan oleh berbagai pemain. Sama halnya dengan suatu pertunjukan, pola dan tingkah laku tersebut berfungsi sebagai penghubung untuk membuktikan motif dan perilaku manusia (West \& Turner, 2010, p. 329). Berikut ini adalah lima dari model dramatistik pentad Burke (West \& Turner, 2010), yaitu:

1. The Act - Apa tindakan yang dilakukan? Adalah penunjukkan, demonstrasi dari tindakan dan pola yang dilakukan oleh tokoh.

2. The Scene - Kapan tindakan tersebut dilakukan?

Menyediakan konteks yang mengiringi tindakan tersebut.

3. The Agent - Siapa yang melakukan tindakan tersebut?

Merupakan seseorang yang menunjukkan tindakan tersebut.

4. The Agency - Bagaimana Agent melakukan tindakan tersebut.

Merujuk pada suatu tindakan lain yang digunakan Agent untuk melakukan tindakan tersebut seperti strategi penyampaian pesan, pidato belasungkawa, penulisan surat permohonan pengunduran diri, negosiasi perdamaian di daerah konflik Suriah.

5. Purpose - Mengapa tindakan tersebut harus dilakukan?

Merujuk pada aims and goals dari apa yang diinginkan oleh agen dalam perbuatannya.

Tabel 1. Bentuk Paralel Pentad

\begin{tabular}{ll}
\hline Act & Response \\
\hline Scene & Situation \\
Agent & Subject \\
Agency & Stimulus \\
Purpose & Target \\
\hline
\end{tabular}

Sumber: Bentuk Paralel Pentad, dari Griffin, 2004, p. 315.

\section{HASIL DAN PEMBAHASAN}

Di dalam film They Live para alien menguasai manusia dengan memanfaatkan sifat serakah manusia yang mudah untuk dipecah belah, para alien mengeksploitasi kondisi hiperrealitas manusia yang kemudian dari hiperrealitas tersebut, para alien menggiring manusia kepada simulacra menggunakan media yang media itu 
sendiri adalah sebagai refleksi dari pola perilaku masyarakat itu sendiri. Para alien memerangkap manusia kedalam realitas palsu yang pada akhirnya terciptalah masyarakat konsumen, sebuah lingkaran setan yang berujung pada kehancuran (Baudrillard, 1994). Hal yang digambarkan oleh film They Live merefleksikan manusia yang selalu berseturu satu dengan sama lainnya, seperti perang, melakukan pengerusakan alam, degradasi moral dan lainnya itu berasal dari manusia itu sendiri, salah satunya adalah sifat berlebih-lebihan dan tidak pernah mau puas. Dalam buku Baudrillard yaitu The Consumer Society: Myth and Structures, menurut Baudrillard (1998), manusia mengkonsumsi suatu produk, barang dan jasa bukan lagi pada nilai guna untuk memenuhi kebutuhan fungsional dari barang atau jasa tersebut namun lebih kepada pemenuhan gengsi dan prestise, pada sistem tanda dan kode. Dengan sistem tersebut berdampak pada munculnya kesenjangan sosial, perbedaan kelaskelas sosial dan menurutnya, bila konsumen tidak berhati-hati, maka akan terjerumus kepada hedonisme (Baudrillard, 1996), dan lebih parah lagi, akan terjerumus kepada nihilisme (Baudrillard, 1994).

Hal-hal tersebut digambarkan dengan jelas di film They Live sebagai kritik pada konsumerisme di adegan awal pembuka film yang mengambarkan kondisi ekonomi dan sosial yang buruk bagi kaum kelas bawah dan kondisi ekonomi dan sosial yang baik bagi kaum kelas atas yang di dalam film They Live mayoritas dari mereka adalah alien yang menyamar menjadi manusia. Selain itu digambarkan lagi di adegan kedua yang dimana terdapat tayangan televisi yang menampilkan banyak tayangan yang menyuguhkan kehidupan ideal, yang jika berhasil dicapai oleh seseorang maka orang tersebut akan mendapatkan kebahagiaan, padahal belum tentu itu menjamin kebahagiaan seseorang namun di dalam film They Live banyak orang yang berlomba-lomba dalam meraih kebahagiaan yang tidak pasti tersebut. Juga di adegan ketiga yang dimana John Nada, masih mempercayai american dream namun ia tempuh dengan cara yang sama dan tidak kreatif, yang berujung pada hidup yang sama saja tanpa ada perubahan sedikitpun, walaupun demikian John merasa nyaman dengan itu, padahal itu tidak baik baginya karena jika ia terus berada di dalam pola pikirnya maka ia tidak akan pernah mendapatkan tempat tinggal yang layak dan akan terus tinggal berpindahpindah tempat dan tetap menjadi tunawisma.

Pada adegan keempat, ketika tayangan televisi diretas oleh seseorang dan orang tersebut berkata "Our impulses are being redirected. We are living in an artifically induced state of consciousness that resembles sleep". Adegan ini menggambarkan aspek simulacra di dalam film They Live, yang dimana masyarakat digambarkan oleh film They Live sebagai masyarakat yang hidup di dalam perangkap simulasi palsu yang semu yaitu konsumerisme, sehingga masyarakat tersebut dapat dengan mudah dikuasai dan diperbudak oleh alien di dalam film They Live. Kemudian orang tersebut melanjutkan kata-katanya "...and we are their unwitting accomplices. Their intention to rule rests with the annihilation of counsciousness. We have been lulled into a trance. They have made us indifferent to ourselves, to others. We are focused only on our own gain. We haPlease understand, they are safe as long as they are not discovered. That is their primary method of survival. Keep us asleep, keep us selfish, keep us sedated". Orang di dalam film They Live tersebut menyinggung tentang hancurnya kesadaran, dibiusnya masyarakat kedalam kesenyapan dan kepasifan pada kejadian sekitar, masyarakat yang terbagi-bagi dan terpecah belah, sikap apatis dan egois. Hal ini merefleksikan kondisi masyarakat secara umum yang menurut Malpas (2005), dalam The Postmodern masyarakat yang semakin menuju kepada nihilisme dikarenakan oleh konsumerisme yang bersinergi dengan pesatnya perkembangan teknologi.

Pada adegan kesebelas di gambarkan di dalam film They Live seorang perempuan kelas atas yang tengah memasukkan banyak barang belanjaannya kedalam bagasi mobil, ia ditemani oleh kedua pembantu rumah tangganya, perempuan itu ternyata berwujud asli alien, hal ini merefleksikan sebagai situasi dan kondisi hiperrealis seseorang yang menjadi simulacra dan dari proses tersebut, orang itu berkontribusi membentuk apa yang dinamakan sebagai masyarakat konsumen. Di adegan kesebelas yang penulis pilih ini perempuan tersebut dengan terus menerus meracau dan berbicara kepada kedua pembantu rumah tangganya sambil memasukkan banyak barang belanjaannya, mereka berdua tampak terlihat tidak tertarik dengan omongan majikannya, hal ini merefleksikan sikap acuh tak acuh dan egoisme sang majikan dengan barang belanjaannya yang banyak dan mahal. Kemudian, masih di adegan yang sama John Nada melihat beberapa perempuan yang sedang berada di sebuah salon, dan perempuanperempuan tersebut ternyata adalah para alien yang menjelema menjadi manusia, digambarkan di dalam film They Live mereka sangat memerhatikan penampilan, simbol dan gengsi, 
dan dalam film ini mereka adalah alien berwajah buruk rupa yang menjelema menjadi perempuan-perempuan cantik, ini merefleksikan buruknya individu-individu konsumeris dan adegan ini adalah sebagai contoh dari simulacra dan konsumsi kompulsif, sebagaimana yang dijelaskan menurut Baudrillard (1983) di dalam Simulations dan menurut Firat, Kutucuoglu, Saltik dan Tuncel (2013) di dalam Consumer Culture and Consumer Society.

Seiring berjalannya waktu dan pesatnya pertumbuhan teknologi, tidak bisa dipungkiri lagi bahwa konsumerisme akan semakin menyebar luas dan masyarakat akan dengan mudah terpapar oleh konsumerisme. Di dalam film They Live, kondisi dunia pada saat itu diwarnai dengan kesenjangan sosial, kriminalitas meningkat, sumber daya alam banyak yang semakin menipis, dan semua itu adalah rencana dari para alien yang menduduki bumi, untuk mengkuras sumber daya alam, hal ini merefleksikan bahwa sikap berlebih-lebihan manusia dapat berujung pada kehancuran manusia itu sendiri, salah satunya dengan cara menenggelamkan diri di dalam pusaran konsumerisme yang hal tersebut berdampak langsung pada psikis dan fisik. Baudrillard (1998) dalam The Consumer Society: Myths and Structures berpendapat bahwa satu-satunya solusi untuk masalah konsumerisme itu terletak pada perubahan dalam hubungan sosial dan dalam logika sosial. Masyarakat membutuhkan logika sosial yang membawa kemakmuran pertukaran simbolis, bukan pertukaran simbolis dengan tujuan prestise semata, masyarakat harus lebih mementingkan bagaimana setiap individu bermanfaat bagi orang lain dan lingkungan, karena menurutnya konsumerisme berbahaya karena menumpulkan rasa empati yang hal tersebut akan membawa masyarakat kepada budaya konsumeris nihilistik. Hal ini jika dibiarkan akan sangat berdampak pada generasi yang akan datang, efeknya adalah jangka panjang.

\section{KESIMPULAN}

Penelitian dimulai dengan sebuah penemuan bahwa film They Live (1988) adalah sebuah film yang mengandung unsur-unsur konsumerisme. Penemuan tersebut penulis dapatkan berdasarkan penggambarkan baik secara verbal maupun non verbal bahwa terdapat unsur-unsur konsumerisme di dalam film They Live (1988) dan terdapat relevansi antara konsumerisme yang digambarkan di dalam film They Live dengan realita masa kini. Relevansi dengan masa kini yang penulis dapatkan tersebut bersifat mencakup semua budaya manusia secara umum dan relevansi konsumerisme yang digambarkan di dalam film They Live (1988) mencakup kehidupan manusia di berbagai dunia.

Melalui hasil analisa dramatistic pentad Kenneth Burke yang terdiri dari act, scene, agent, agency, purpose terhadap pesan verbal dan non verbal dalam film They Live, penulis menemukan bahwa:

1. Film They Live tersebut secara jelas menggambarkan bagaimana fenomena konsumerisme yang berdampak buruk bagi masyarakat di dalam film They Live. Dampak buruk tersebut berdasarkan penggambaran masyarakat di dalam film They Live adalah seperti acuh tak acuh dengan sesama manusia dan lingkungan, pandangan-pandangan manusia yang hanya memikirkan dirinya sendiri, nihilisme, apatis dan kehidupan yang monoton, kerja, hidup dan mati. Sifat egoisme dalam masyarakat di film tersebut berakibat pada habisnya sumber daya alam, rusaknya lingkungan akibat budaya konsumtif yang berlebihan dan degradasi moral. Selain penggambaran konsumerisme secara umum, didapatkan juga penggambaran simulacra dan hiperrealitas secara spesifik di beberapa adegan tertentu.

2. Ditemukan juga relevansi dari konsumerisme yang digambarkan di dalam film They Live dengan realita masa kini. Konsumerisme pada film They Live tampak semakin nyata dengan realita masa kini dikarenakan cepatnya perkembangan teknologi sehingga konsumerisme dapat menyebar dan tidak terbatas hanya dengan media televisi dan papan billboard sebagaimana yang digambarkan di dalam film They Live namun konsumerisme era masa kini menyebar melalui internet.

Selain itu, terdapat juga adanya penggambaran media sebagai refleksi masyarakat. Masyarakat yang di gambarkan di dalam film They Live terlihat tidak peduli, egois dan berlebih-lebihan dalam cara berfikir dan dalam kehidupannya, media yang di gambarkan di dalam film juga bersifat sebagaimana masyarakat. Media yang ada di dalam film They Live, seperti maraknya iklan-iklan konsumeris, adalah refleksi dari masyarakat, karena jika masyarakat yang ada di dalam film tersebut saling peduli dan aktif dalam menyikapi kejadian yang ada di sekitarnya, para makhluk luar angkasa tersebut tidak akan dengan mudah menguasai dunia, 
mengekspolitasi manusia dan sumber daya alam bumi.

\section{REFERENSI}

Baudrillard, J. (1983). Simulations.

Semiotext[e].

Baudrillard, J. (1983). Simulations.

United States: Semiotext[e].

Baudrillard, J. (1994). Simulacra and

simulation. (S. Glaser, Trans.) Ann Arbor, Michigan, United States of America: University of Michigan Press.

Baudrillard, J. (1996). The System of

Objects. (J. Benedict, Trans.) London and New York: Verso Books.

Baudrillard, J. P. (1998). The Consumer

Society: Myths and Structures. In J. P. Baudrillard, The Consumer Society: Myths and Structures. London: SAGE.

Britannica, T. E. (2014, Juli 31). Jean

Baudrillard. Retrieved November 1, 2017, from Encyclopædia

Britannica: https://www.britannica.com/biography/JeanBaudrillard

Britannica, T. E. (2017, Juni 05). Kenneth Burke. (T. E. Britannica,

Editor) Retrieved November 1, 2017, from Encyclopædia Britannica: https://www.britannica.com/biography/Kennet h-Burke

Bryant, J., \& Zillmann, D. (2002).

Media Effects: Advances in Theory and Research (2nd ed.). Mahwah, New Jersey, United States of America: Lawrence Erlbaum Associates.

Conley, D. (2013). You May Ask

Yourself: An Introduction to Thinking Like a Sociologist (3rd ed.). New York: W.W. Norton.

Daymon, C., \& Holloway, I. (2011).

Qualitative Research Methods in Public Relations and Marketing Communications. New York: Routledge.

Franco, L. (Producer), Carpenter, J.

(Writer), \& Carpenter, J. (Director). (1988). They Live [Motion Picture]. United States of America: Universal Pictures.

Griffin, E. (2012). A First Look At

Communication Theory. New York: The McGrawHill Companies, Inc.

imdb.com. (1988). They Live. Retrieved

from

http://www.imdb.com/title/tt0096256

Littlejohn, S. W., \& Foss, K. A. (2008).

Theories of Human Communication. Belmont: Cengage Learning.

Malpas, S. (2005). The Postmodern.

New York: Routledge. Merriam-

Webster. (n.d.). Retrieved from Simulacra: http://www.merriam-

webster.com/dictionary/simulacrum

Perse, E. M. (2001). Media Effects and

Society. New York: Routledge.

Underground, E. O. (2016, Juni 6). They Live in
John Carpenter's Own

Words. youtube.com.

West, R., \& Turner, L. H. (2000).

Introducing Communication Theory: Analysis and Application. New York: McGraw-Hill.

West, R., \& Turner, L. H. (2010).

Introduction Communication Theory: Analysis and Application. New York: McGraw-Hill.

\section{PROFIL PENULIS}

Berikan penjelasan singkat mengenai profil penulis 